\title{
Object models of IT-systems supporting cognitive structures in novice courses of Informatics
}

\author{
Peter Hubwieser \\ Department of Informatics, Technische Universität München, 80290 München, Germany
}

\section{Peter.Hubwieser@in.tum.de}

Key words: Basic Concepts, Cognition, Curriculum Policies, Informatics, Secondary Education

Abstract: Designing a new mandatory subject of informatics for the 6th grade of the Bavarian Gymnasiums we decided to use a certain type of object modelling to bridge the gap between two almost opposite objectives. The first was to enable the students to use IT-systems in a competent and autonomous way - the second to teach durable and transferable basic concepts. While some criticisms have been levelled against the benefits of mental models, we rely on these mental models to support our novice students in applying and mastering ITsystems. Our views are supported by some recent results from pedagogical psychology. In this paper we present a suitable modelling technique that will be used in the novice course of the new subject and some results of the first evaluations of the preliminary pilot courses.

\section{INTRODUCTION}

Following years of confused discussion whether informatics in schools should be implemented in the form of a mandatory, dedicated subject or integrated within other subjects like Mathematics, Languages or Science, the conclusion that it is necessary to combine these policies is gaining acceptance in Germany. This is caused by three main factors:

- It is absolutely necessary that nearly all school subjects should make use of the opportunities that are offered by e-learning. 
- In nearly every subject the consequences of the information society on the specific subject area are discussed.

- In the near future virtually all students will have free access to a computer (currently $97 \%$ of 11 year-olds have access) with a rich software resource.

Students have demonstrated that they are able to acquire basic user skills without guidance (Mitra and Rana 2001). It is therefore no longer necessary to offer them just access to hardware and software systems or to drill basic user skills, but to teach them how to use IT-systems competently and help them answer the questions that are posed to them during the use of these systems:

- How does that machine work?

- What are the basic concepts involved in its construction?

- What are the limitations of its use?

- How can I really control its affects?

The only possible reaction to these insights is to make considerable use of IT-systems, to reflect and discuss their consequences throughout the curriculum, to teach basic concepts that are essential for a real understanding of the working principles of systems and master their usage within a dedicated subject called "informatics".

\section{A NEW SUBJECT CALLED "INFORMATICS"}

As a result of these considerations Bavaria decided to introduce, from 2003, a new, mandatory subject "informatics" in the $6^{\text {th }}$ grade at all its 400 Gymnasiums. Each year this will involve about 50,000 eleven to twelve year-old students. Currently we are testing the concept with regard to content and teaching methods at 20 schools, involving about 40 classes and 1200 students.

This new subject has to meet the demands of a broad variety of different social groups like companies, universities, parents, students and teachers. Long and intensive discussion beneath these groups showed there should be two central objectives which, at first glance, appeared to be diametrically opposed:

- the students should be taught the application of certain specific and wide-spread IT-systems (graphic and word-processors, web editors, email clients) to real-life situations;

- the acquired skills and concepts should be valuable for a very long time, even after their period of education, and should be transferable over a broad variety of systems. 
We tried to satisfy these demands by offering a teaching concept that stimulates the students to explore long-lasting structures (which might serve as mental models to support real understanding) as well as encouraging them to work extensively on documents using a set of modern, well-known standard software systems.

\section{MENTAL REPRESENTATIONS}

With regard to mental models we have to ask ourselves if human beings really use a situation-independent mental representation before the application of any tool. This seems obvious from a common-sense rationalistic point of view but there are strong arguments against this, notably the criticism of Winogard and Flores (1986) who quote the philosophy of Heidegger and the experimental results of Manturana.

Heidegger claims that a highly skilled craftsman like a carpenter usually is not aware about the hammer he is using. Instead he has a "readiness by hand" attitude towards the hammer, which operates outside his consciousness until the hammer is not where it is expected to be or not working properly. This causes "breakdown" and finally draws the attention of the craftsman to the tool.

Maturana investigated the retina of frogs and detected that their perception, e.g. of a fly, was not based on a formal representation of the fly but emerged as a local variation of light compared to the surroundings. The result inspired Maturana to his radical constructivism, regarding all living things as closed "autopoietic systems". The adaptation of these radical constructivistic biological concepts to the context of human learning contributed to the development of moderated approaches, such as the "situated cognition concept" (Gerstenmaier and Mandle 1996). This assumes human mental models, which result from the learning process, are not only dependent on the taught concept, but also on the situation and the context in which they were acquired.

Nevertheless we are convinced that mental representations are used during the application of a tool under at least one of the three following circumstances:

- the user is a novice concerning the tool;

- the tool has a very complex structure;

- the tool is used in a very complex application domain.

All these circumstances are satisfied when eleven year-old students are learning to use and apply standard software systems. As Winograd and Flores (1986) conclude "Human cognition includes the use of representations, but it is not based on representations." 
We claim that under the circumstances described above mental models (regarded as representations) are at least helpful. Consequently we wish to identify which kind of mental models will help the students to use the systems most efficiently. Results from modern pedagogical psychology and recent developments of software engineering models offer help in this identification.

\section{MODELLING TECHNIQUES}

\subsection{Cognitive Mapping Techniques}

During the past decades a variety of mapping techniques has been explored in the field of pedagogical psychology. The techniques were used to enhance learning processes, to support the revision of concepts or strategies and to foster the acquisition of cooperation skills or analyse the modelling of learning processes (the last by enabling qualitative measures of learning results).

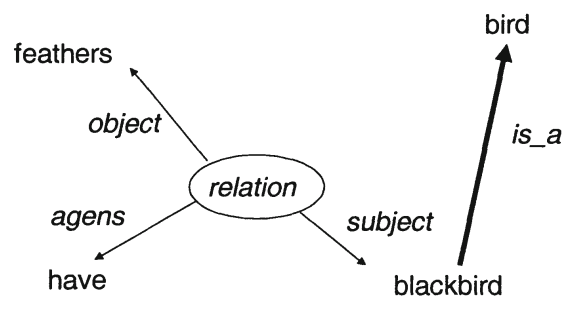

Figure 1. Propositional network

One of the first generally accepted techniques was the concept of Propositional Networks (Figure 1) (Rumelart et al 1972). This was originally designed to graphically represent the structure of human cognition. The graphs consisted of two kinds of nodes (concepts and relations) and edges which symbolized subject, object and agents in the context of relationrespective generalization ("is-a" relation). Based on this a number of techniques followed, such as Concept Maps (Jüngst 1992) and Expert Maps (Boothby and Alvermann 1984). The former use nodes to signify concepts and additional information (e.g. restrictions) and marked edges to assign relations (e.g. generalisation and aggregation - Figure 2). Expert maps use nodes to symbolize concepts and constraints and unmarked, but weighted, 
edges to represent different types of connections between the nodes (Figure $3)$.

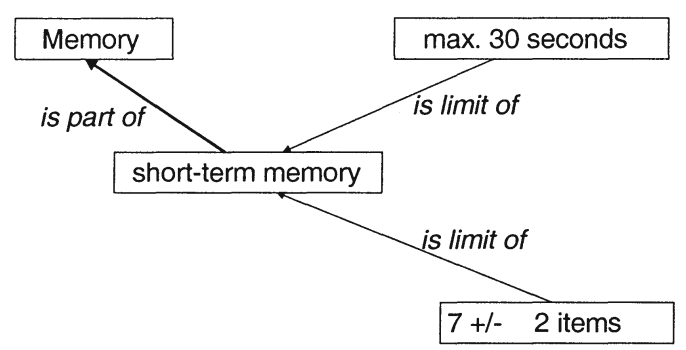

Figure 2. Concept map

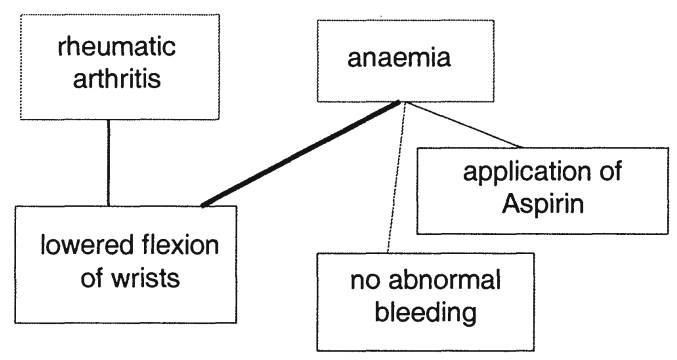

Figure 3. Expert map

The application of these graphs was intensively evaluated and showed some remarkable results:

- concept mapping techniques improved the memory capacity compared with textual representations;

- expert map sequences supported the application of concepts;

- concept mapping techniques supported the coordination of conceptual and numerical knowledge during the application of physical formulae (Mandle and Fischer 2000). 


\subsection{Software Models}

Simultaneously with the development of mapping techniques by pedagogical psychologists graphical modelling techniques were developed in software engineering, culminating in the cooperative design of the current de facto standard, the Unified Modelling Language, by key protagonists of Object Oriented Software Modelling (Booch et al 1997). This was not a fortuitous correspondence - these object models were a very specific adaptation of psychological Concept Maps to the needs of software developers and their customers. The success and broad acceptance of these techniques demonstrate that they are very sustainable for supporting communication about IT-systems. Parts of them may be applicable within our teaching concept.

\section{CONCEPTION OF THE $6^{\mathrm{TH}}$ GRADE}

\subsection{The Model Construction Kit}

Impressed by the success of these mapping and software modelling techniques we decided to base our concept for the new Bavarian subject of informatics on graphical object-oriented models of ICT-systems. These are very similar to the mapping models used in psychology and to the models of the software developers.

Taking the age of the students into consideration, we designed our Model Construction Kit in a similar way to a box of building blocks. It contains the following concepts that, at the end of the course, enable the students to model a Hypertext structure or a roboter:

- objects, classes, attributes, methods and messages;

- relations between objects and classes; aggregation and other associations;

- structures of algorithms; sequence and repetition of instructions, conditional instructions.

Specific notations are used to describe these concepts:

- object diagrams symbolizing structures of real objects;

- class diagrams describing structures of "abstract" classes as descriptions of real objects;

- formal pseudo-code to ease compaction and exact communication. 


\section{$5.2 \quad$ Introduction step by step}

Starting with the elaboration of the basic concepts ("object", "attribute" and "class") in the context of vector graphics (Figure 4), we develop the models by introducing the concept of aggregation (e.g. paragraphs containing characters) in the context of text processing.

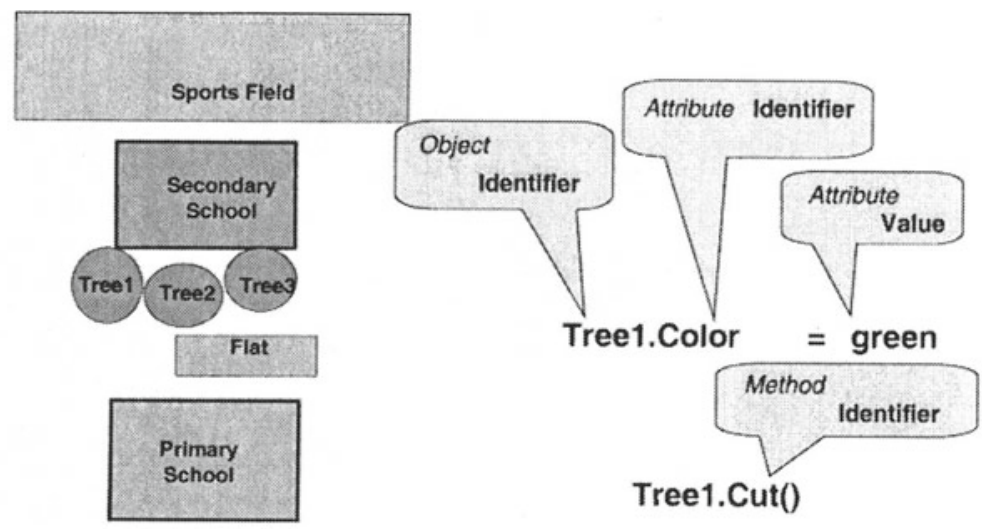

Figure 4. Objects of vector graphics

Subsequently the students encounter the first recursive aggregation, presented by the example of folders that contain other folders (Figure 5).

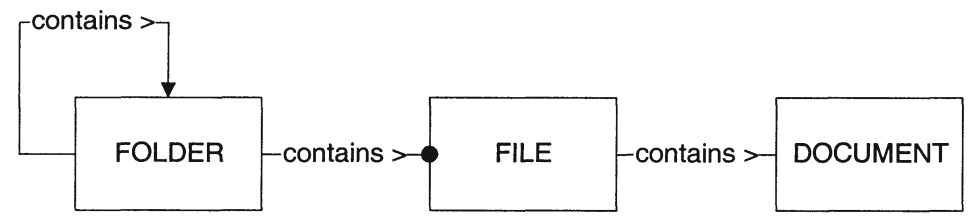

Figure 5. Class diagram - folders containing folders

This enables the development of folder trees, used to represent hierarchical structured information. Later the graphs are extended by the concept of links in the context of hypertext systems. This permits the construction of cyclic graphs (Figure 6). Finally we start to program our own methods using a virtual roboter using "built-in methods" like "forward", "turn left" and so on (Figure 7). 


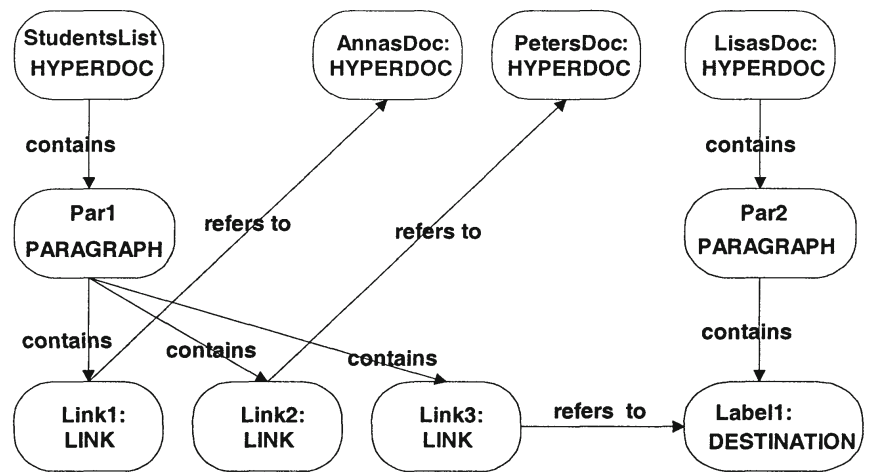

Figure 6. Object diagram - hypertext structure
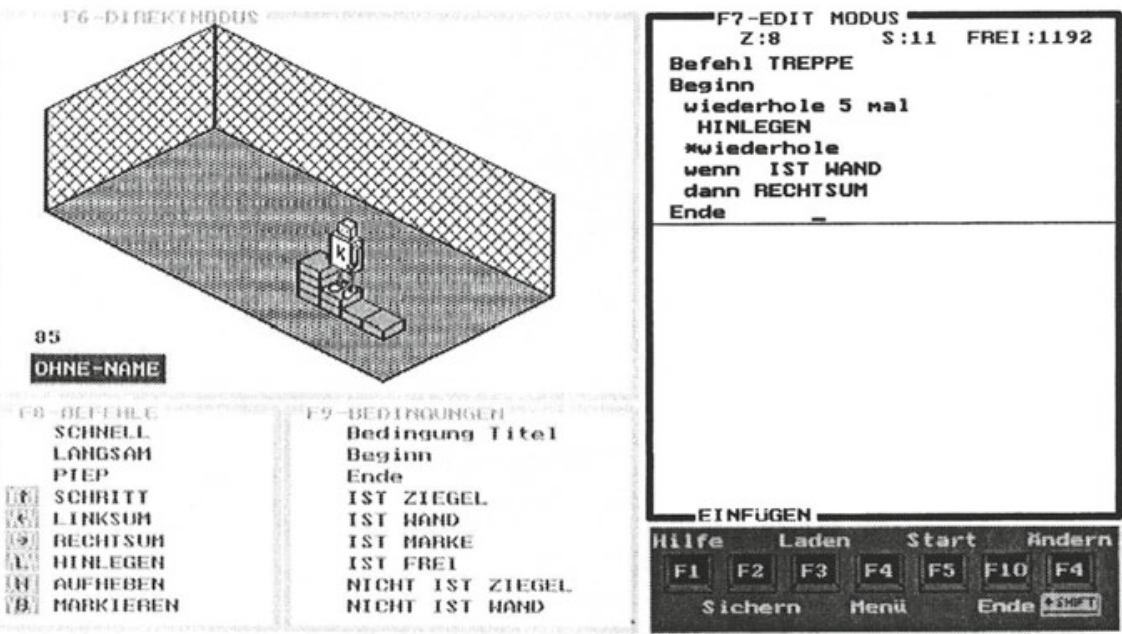

Figure 7. Roboter

\subsection{Teaching methods}

We emphasize the use of constructivist and integral learning approaches as much as possible. This includes extensive usage of hardware and software systems to construct and edit a variety of documents, representing information and analysing its structures. Visual and haptic illustrations are also considered very useful - for instance the use of wooden stick sets to 
construct folder trees or the symbolization of an hypertext graph by connecting papers (documents) by woollen threads (links) on a pin-board (Figure 8). All new concepts are introduced by reflecting and analysing the products of the students - drawings, hypertexts, e-mails or self-made roboter programs.

Modern constructivist teaching approaches are supported - for instance:

- Cognitive Flexibility by using multiple representations of the same structure (pseudo-code, object model, class model and the document itself on the software system).

- Narrative Anchors by integrating the student tasks with thrilling tales.

- Cognitive Apprenticeship by working in authentic office environments and using professional software development techniques.

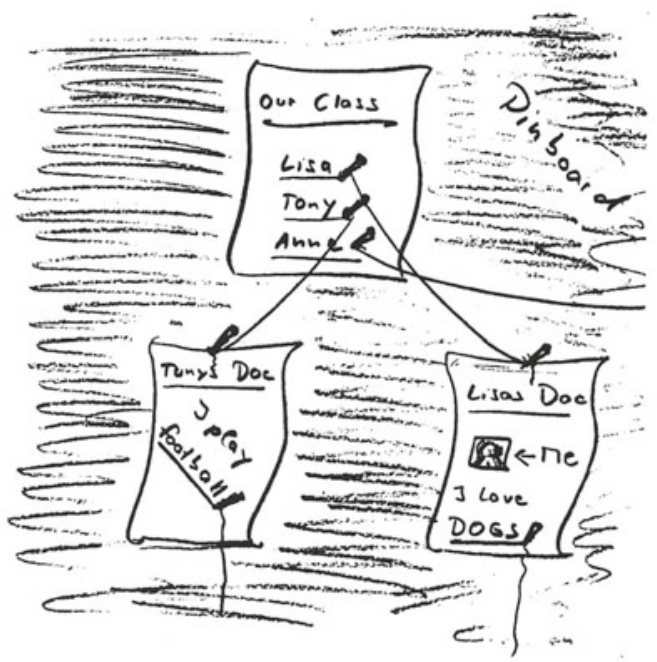

Figure 8. Visualisation of hypertext structure at a pinboard

\subsection{The Software Toolkit}

First of all we apply a very simple graphic processor. This should be supplemented by use of a pixel-oriented painting program. For text structuring a common word processor will suffice. The choice of a suitable hypertext editor is more difficult. Students should not be forced to learn the syntax of Hypertext Markup Language - they should be introduced to a "what-you-see-is-what-you-get" tool with not too many features. If possible, the software should offer a graphical representation of the hypertext 
structure. Finally the algorithmic structures require a virtual roboter system such as "Karol the Robot" (http://www.schule.bayern.de/karol).

\subsection{More than user skills}

Using our methodology we enhance the information processing skills of the students and enable them to understand the basic structure of the systems they use.

We certainly stimulate them to think about the basic structures of the documents they produce (which are very long lasting) in contrast to remembering sequences of product and time dependent terms associated with a specific user interface e.g. menu-entries, checkboxes or hot-keys. The benefits of this principle, compared with the usual drills of pure user skills on a specific system, can be illustrated by the following:

- Multiple calls. "Copy", which is common to objects of many different classes, might be invoked by activating a sequence of menu entries (Edit - Copy), by clicking on a symbolic icon on a task bar (a pair of scissors) or by simultaneously pressing a combination of keys (ctrl - c). The result is always the same.

- Documents and files. Careful differentiation between the classes "document" (whose objects are located in the working memory of an application) and "file" (whose objects are located on persistent data storage devices) enables students to understand the process of saving and opening a document. "Save" is a method associated with the class document, whose calls are automatically redirected to calls of "save as" as long as there is no file name for the document. However, "open" is (originally) a method of the class "file" (possibly calling a corresponding method of the contained document) which uses the name of an application as a parameter and allows us to open a file (using the file manager) before opening the corresponding application.

- Clipboard. The interpretation of a clipboard as an object that may contain every other object that is part of a document makes it easy to describe the working principles of the methods "cut", "copy" and "paste". The call of an objects method "copy" results in copying itself into the clipboard. This enables the call of the copied objects method "paste", which results in an insertion into the active document. 


\section{THE FIRST RESULTS}

After the completion of the first year of the experimental $6^{\text {th }}$ grade, teachers of 28 classes asked their 728 students (62\% boys, $38 \%$ girls) some questions to investigate their attitude towards the new subject. Simultaneously the teachers had to answer other questions concerning the completion of the syllabus and the software which had been used. Most importantly $81 \%$ of the students liked the subject - only $14.6 \%$ didn't. Compared to mathematics $58.5 \%$ considered informatics was easier, $19.9 \%$ comparable and $8.1 \%$ felt it was more difficult.

Concerning the syllabus only one of the 28 classes skipped a software topic (hypertext), while four classes did not use object diagrams. All other classes covered the syllabus in full.

Simultaneously the University of Dortmund carried out videosupervision of the project (Hubwieser et al 2001). This confirmed that the object-oriented modelling technique served as a bridge to connect previously known concepts with new ones. It also showed that the students, as a consequence, used the correct technical terminology.

\section{CONCLUSION}

In our opinion this teaching concept is transferable not only to other lower grades in secondary schools but might, in part, be applied to user training courses on standard software. These often show a deficit in teaching structure and thus lack durability and generality

\section{REFERENCES}

Boothby, P. R., Alvermann, D. E. (1984) A classroom training study: Effects of graphic organizer instruction on fourth graders' comprehension. Reading World, 23, pp. 325-335.

Booch, G., Rumbaugh, J. and Jacobson I. (1997) Unified Modelling Language - Semantics and Notation Guide 1.0. Rational Rose Software Corp., San Jose, California.

Gerstenmaier, J. and Mandl H. (1995) Wissenserwerb unter kognitivistischer Perspektive. Zeitschrift für Pädagogik 41, pp. 867-888.

Hubwieser, P., Humbert L. and Schubert S.(2001) Evaluation von Informatikunterrich. (Werkstattbericht). In Informatikunterricht and Medienbildung. INFOS 2001, GIFachtagung "informatik und Schule", R. Keil-Slawik and J. Magenheim (eds.), Paderborn. GI-Edition Lecture Notes in Informatics. Bonn, pp. 213-215.

Jüngst K.L. (1992) Lehren und Lernen mit Begriffsnetzdarstellungen. Zur Nutzung von concept-maps bei der Vermittlung fachspezifischer Begriffe in Schule, Hochschule, Ausund Weiterbildung. Afra, Frankfurt am Main. 
Mandle H. and Fischer F. (2000) Wissen sichtbar machen. Wissenmanagement mit MappingTechniken. Hogrefe, Göttingen.

Mitra S. and Rana V. (2001) Children and the Internet: Experiments with minimally invasive education in India. British Journal of educational technology 32, No. 2, pp. 221-232.

Rumelart D. E., Lindsay P. and Norman D. A. (1972) A Process model for Long-term Memory. In Organization of Memory, E. Tulving and W. Donaldsen (eds.), Academic Press, New York.

Winograd T. and Flores F. (1986) Understanding Computers and Cognition. A new Foundation for Design. Ablex Publishing Corporation, Norwood, New Jersey. 